CREATIVE REASONING IN FORMAL OISCUSSION

Erik C.W. Krabbe

Department of Philosophy

University of Utrecht

Logic Group

Preprint Series

No.22

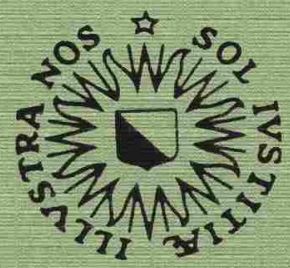

Department of Philosophy

University of Utrecht 
CREATIVE REASONING IN FORMAL DISCUSSION

Erik C.w. Krabbe

Department of Philosophy

University of Utrecht

June 1987

Department of Philosophy

University of Utrecht

Heidelberglaan 2

3584 CS Utrecht

The Netherlands 


\section{CREATIVE REASONING IN FORMAL DISCUSSION}

\section{ERIK C. W. KRABBE}

\section{Faculteit der Wijsbegeerte}

Rijksuniversiteit te Utrecht

Heidelberglaan 2

NL 3584 CS Utrecht

The Netherlands

ABSTRACT: Systems of formal dialectics articulate methods of conflict resolution. To this end they provide norms to regulate verbal exchanges between the Proponent of a thesis and an Opponent. These regulated exchanges constitute what are known as formal discussions.

One may ask what moves, if any, in formal discussions correspond to arguing for or against the thesis. It is claimed that certain moves of the Proponent's are properly designated as arguing for the thesis, and that certain moves of the Opponent purport to criticize the tenability or the relevance of the reasons advanced. Thus the usefulness of formal dialectic systems as models for reasonable argument is vindicated.

It is then proposed to make these systems more realistic by incorporating in them a norm of Creative Reasoning that removes the severe restrictions to which the Proponent's arguing was hitherto subject. As a consequence, a certain type of irrelevant reason is no longer automatically excluded. Therefore, it is proposed to extend the Opponent's rights to exert relevance criticism. The new dialectic systems are shown to be strategically equivalent to the original ones. Finally, it is stressed that the Opponent's criticism should not be designated as arguing against the thesis. The Opponent criticizes, but does not argue.

KEY WORDS: Argumentation, concession, creative reasoning, formal dialectics, formal discussion, relevance, tenability, winning strategy.

\section{INTRODUCTION*}

Do the parties involved in a formal discussion argue? And, if so, which of their moves should count as arguing?

In these questions the term 'formal discussion' refers to regimented discussions defined by systems of formal dialectics (here dubbed 'standard systems') such as one finds 
expounded in detail by Barth and Krabbe (1982), who provide normative foundations for a number of dialogue games of the type studied in dialogical logic. Thus, their work rests on that of the founders of dialogical logic, P.Lorenzen and K.Lorenz, whose classical papers are collected in Lorenzen and Lorenz (1978). A brief description of the general features of formal dialectics is published as Section 2.1 of Krabbe (1985a), an explanation of its normative and hierarchically ordered foundations is found in Barth (1982).

As to the term 'arguing', let it suffice to note that I take this word in the somewhat restricted sense of arguing for or against some thesis (expressed opinion, conclusion) by propounding certain propositions that are to serve as reasons for or against it. Hence, critical questions and expressions of doubt do not by themselves count as instances of arguing.

\section{A PROPONENT'S REASONS AND AN OPPONENT'S CONCESSIONS}

In a simple conflict of avowed opinions there is only one thesis, upheld by one of the parties in the conflict. The other party has expressed its doubt with respect to the thesis; it may or may not have conceded a number of points. To resolve their conflict, the parties may avail themselves of a system of formal dialectics: they may decide to start a formal discussion according to the rules of such a system. If so, one of the parties should take the part of the Proponent (P) and the other that of the Opponent (O). P is to defend the initial thesis, and $\mathrm{O}$ is to criticize it, in accord with the rules of the system. In the defense, $\mathrm{P}$ can profit from O's concessions, which, in a sense, serve as premisses of P's argument.

In their discussion of dialogical logic, Van Eemeren and Grootendorst (1984, pp. 13, 14) are surprised to find the statements they deem to constitute the Proponent's argument equated with the Opponent's concessions. Their bewilderment seems justified:

If one imagines a dispute about an expressed opinion between $A$ and $B$, it seems rather strange if A simply takes over B's argumentative statements. We believe that in practical argumentation one language user is unlikely simply to take upon himself an obligation to defend statements which are in principle the other language user's premisses. As a rule the initial situation that the dialogic logicians take as their starting point will, in our view, be preceded by an earlier one which may or may not lead to it. ${ }^{1}$

According to Van Eemeren and Grootendorst, there is a crucial difference between an initial conflict situation such as described by the dialogical logicians and what normally forms the starting point of an argumentative discussion. The former type of conflict, they say, occurs only at a later stage of an actual discussion (if at all). It occurs when the disputants (called by them Protagonist and Antagonist) decide to test the defensibility of the initial thesis in relation to the argument that has been advanced for it. But then, this 
argument must have been advanced at some earlier stage, presumably by the party that is positively committed to the thesis, i.e., the Protagonist. In order to test the relative defensibility of the thesis, the parties may agree to engage in a formal sub-discussion and assume the dialectical roles of Proponent and Opponent. Assuming that the Protagonist figures as the Proponent and the Antagonist as the Opponent, the Antagonist will during the formal discussion be positively committed to the argument (the reasons) advanced earlier by his or her adversary.

Van Eemeren and Grootendorst illustrate the different types of initial conflict by means of the following examples (see Figure 1 and Figure 2). ${ }^{2}$

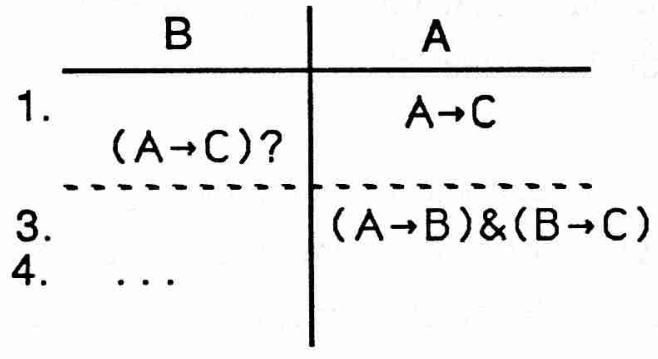

Fig. 1

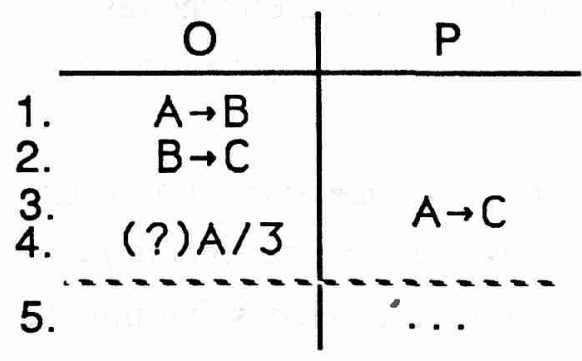

Fig. 2

In Figure 1 the Protagonist (A) advances a positive point of view and, therefore, is positively committed to the initial thesis, $A \rightarrow C$. The Antagonist (B) challenges the Protagonist to argue for his or her point of view (line 2). The Protagonist, not taking it lying down, promptly reacts on line 3. According to Van Eemeren and Grootendorst, the initial situation of the dispute in Figure 1 (depicted above the dashed line) is of the type that normally occurs, whereas the dialogical logician's initial situation is depicted above the dashed line in Figure 2 . The initial situation of Figure 2, however, could occur only after line 3 of Figure 1. In that situation A and B agree to test the defensibility of A $\rightarrow C$ in relation to the argument advanced by $\mathrm{A}$ on line 3 of Figure 1 . They decide to do so by means of a formal discussion (having agreed upon some dialectic system). In this formal discussion, B takes the part of the Opponent and A that of the Proponent. We see that B is now positively committed to the reasons advanced by $A$ in support of his or her thesis, at least as long as B acts as the Opponent in the formal discussion. ${ }^{3}$

Obviously, Van Eemeren and Grootendorst found a way to make use of the standard formal dialectic systems, namely, to incorporate them into a system for argumentative discussion as a means to which the parties may resort as soon as the defensibility of a thesis in relation to the argument advanced is called into question. Formal discussions will then be sub-discussions of larger argumentative discussions that are defined in some other way. The question is whether this is the only occasion where formal discussion would be a suitable instrument.

If the standard dialectic systems are to be taken seriously as normative models for reasonable argument, it seems that some other interpretation of the Opponent's concessions must be found, and that some other stages of formal discussions must constitute the Proponent's arguing. The existence of a particular interpretation of the initial conflict 
situation (in dialogical logic), such as that given by Van Eemeren and Grootendorst, does not establish the inadequacy of the standard systems as instruments for conflict resolution or models of reasonable argument, provided the following two questions can be answered affirmatively:

QUESTION 1. Can one interpret an Opponent's initial concessions in some other way than as an adoption of the Proponent's reasons?

QUESTION 2. Are there moves in formal discussion that one can interpret as a Proponent advancing reasons for the initial thesis?

The Opponent's concessions. Let us start with the first question: in dialogical logic the initial concessions are statements to which party $O$ is positively committed. It is not assumed in formal dialectics that initial concessions are always available, but if they are available, party $P$ can use them in its defense. But why equate the Opponent's initial concessions with the Proponent's reasons? Besides the one dialectic context discussed by Van Eemeren and Grootendorst, there are many others in which a party may be willing to concede some points. First, there are those statements made by $\mathrm{O}$ to which $\mathrm{O}$ is strongly and positively committed and that could figure as an initial thesis in some other discussion with $\mathrm{O}$ taking the part of the Proponent. Second, there are propositions that count as obvious or evident (within a certain company), and $\mathrm{O}$ may be presumed to concede these, unless he or she denies them explicitly. Third, there are perhaps propositions that $O$ will have to admit on account of his or her social position, creed, etc. Thus, in argumentative practice there are ample occasions in which the defender of a point of view presumes, and is entitled to presume, that his or her critic is positively committed to some propositions.

In practice many of these propositions are not stated, whereas in the initial situation of a formal discussion they are explicitly listed on the Opponent's side. But one would not expect a logician's model of argumentation to agree with practice in this respect. Formal dialectics boldly requires that all statements be fully explicit. Consequently, in formal disalectics one is not concerned with the reconstruction of implicit elements of an argument. This task is left to other theories (speech act theory, discourse analysis), whereas it is the logician's task to model the logical core of discussions. ${ }^{4}$ When judging the adequacy of formal dialectics as a model of reasonable argument, one should keep in mind that the restricted aim of formal dialectics necessarily leads to some strong idealizations. The initial conflict situations of dialogical logic are idealisations that fairly correspond to what is normal. The initial situation of Figure 2, for instance could adequately represent some actual confrontation.

To interpret the initial concessions as an adoption of P's argument by $\mathrm{O}$ is not, therefore, the only or even the most obvious way to view them. For the other concessions, namely, those elicited from $\mathrm{O}$ in the course of the discussion, such an interpretation hardly deserves consideration (with exception of the concessions made in accord with the creative 
rule $\mathrm{FD} \mathrm{C} 2$ introduced below).

The Proponent's reasons. As a preliminary to my treatment of the second question, I shall briefly sketch the structure of formal discussions. ${ }^{5} \mathrm{~A}$ fuller account can be obtained from the literature mentioned in the introduction.

Given some initial conflict situation, the first move in a formal discussion is always an attack by $\mathrm{O}$ on the initial thesis. By way of example, we may suppose that the initial thesis is some disjunction $A \vee B$. Let us assume that party $P$ is not willing, at this moment, to commit itself to either of the alternatives, A or B, and further that there are some concessions for $\mathrm{P}$ to exploit. O's attack will then not be answered directly, since the rules will allow party $\mathrm{P}$ first to question party $\mathrm{O}$ on account of its concessions. This questioning is called indirect or counteractive defense. ${ }^{6}$ Each question is to be answered immediately. Since the answers constitute new concessions, the supply of concessions will grow, and new occasions for questioning will come up.

Usually P's questions are noncommittal, but some of them involve commitment to a new statement. The standard example is provided by a concession of the form $C \rightarrow D$. To make use of this concession, party $\mathrm{P}$ is to state, and commit itself to, $\mathrm{C}$. The new concession $\mathrm{P}$ is trying to obtain in this way is $\mathrm{D}$. At this point there is a choice for $\mathrm{O}$ : it may either attack $C$ or concede $D$. Let us assume, for the moment, that $O$ prefers to make a concession in such cases.

Possibly $\mathrm{P}$ will manage to win the discussion in this way, for instance, when $\mathrm{O}$ is made to concede the thesis in the end. Otherwise, $\mathrm{P}$ will, after some questioning, and in view of the enlarged set of concessions, feel strong enough to face O's original attack head-on and offer a so-called direct, or protective, defense of the thesis. In the case of a disjunctive thesis $\mathrm{A} \vee \mathrm{B}$, this means that $\mathrm{P}$ chooses one of the alternatives, $\mathrm{A}$ or $\mathrm{B}$. Let us assume that party $P$ states and commits itself to $A$.(What if $P$ never feels like making this choice? Well, actually P's feelings do not matter, the rules of dialectics will make it impossible for $\mathrm{P}$ to postpone a choice at all times.) As soon as party $\mathrm{P}$ has made its choice, party $\mathrm{O}$ is to attack P's new statement, $A$. This marks the end of the first so-called local discussion and starts a second one in which $\mathrm{P}$ is to defend the local thesis A. After the second local discussion there may follow a third, and so on, until either $P$ wins (this happens, for instance, whenever $\mathrm{O}$ is made to concede the local thesis) or P's possibilities of direct and indirect defense become exhausted, in which case $\mathrm{O}$ wins the discussion.

Let us now return to the question of what happens if, in reaction to P's questioning in regard to a concession $\mathrm{C} \rightarrow \mathrm{D}, \mathrm{O}$ prefers to attack P's statement of C. Once more, O's attack will start a new local discussion, this time with $\mathrm{C}$ as its local thesis. To sum up, all attacks by $\mathrm{O}$ start new local discussions, and the local thesis is, in each stage of the debate, the most recently attacked of P's statements.

In this general set-up, which statements of $P$ could count as reasons for the initial thesis? We are looking for moves in which $P$ uses a declarative sentence to state a proposition in order to defend the thesis. So questions won't do (unless $\mathrm{P}$ makes a 
statement as well, when asking them), and neither will the exclamatory utterances by which P claims to have won a chain of arguments. ${ }^{7}$ In all other moves, i.e., questions involving commitment to a statement and direct defense moves, $\mathrm{P}$ utters some declarative sentence in support of the local thesis. Hence in these moves $\mathrm{P}$ is arguing for the local thesis. This may be obvious as far as P's direct defense moves are concerned,but holds as well for the statements made in the context of an indirect defense move. For instance, consider an indirect defense move consisting of a question targeted on the concession $\mathrm{C} \rightarrow \mathrm{D}$, so $\mathrm{P}$ states $\mathrm{C}$. The current local thesis is being defended relative to the concession $\mathrm{C} \rightarrow \mathrm{D}$, therefore arguing that $\mathrm{C}$ seems prima facie relevant for P's defense: presumably $\mathrm{P}$ wants to make $\mathrm{O}$ admit, first $\mathrm{C}$ then $\mathrm{D}$ and, after some more intermediate steps, the local thesis itself. So $\mathrm{C}$ is a, perhaps remote, reason for the local thesis. Since the local thesis itself is advanced in support of the preceding local thesis, etc., we may say that all the moves supporting some local thesis ultimately support the initial thesis.

Whenever, in an argumentative discussion, a party has advanced some reason for a point of view, one would expect its critic to react according to either of two main lines of criticism: the critic could express doubt with respect to the tenability of the proposition stated, or he or she could criticize the relevance of the stated reason for the point of view that it should support. ${ }^{8}$ At least, one would expect a system of dialectic rules to permit these two types of reaction. Van Eemeren and Grootendorst explicitly formulate a rule to this effect. ${ }^{9}$ Let us see how the rules of formal dialectics fare in this respect. Do they allow the Opponent to exert both tenability and relevance criticism?

Consider first the statements $\mathrm{P}$ makes in the context of an indirect defense move. Let $\mathrm{C} \rightarrow \mathrm{D}$ and $\mathrm{C}$ be stated as before. In formal dialectics there are now actually two options for $\mathrm{O}$ : it may either attack $\mathrm{C}$ and make $\mathrm{C}$ the thesis of a new local discussion (tenability criticism), or it may doubt the relevance of $C$ with respect to the defense of the current local thesis and concede $\mathrm{D}$. Why does conceding $\mathrm{D}$ constitute a form of relevance criticism on C? We noted that the reason $C$ is operative through a chain of intermediate propositions, passing through $\mathrm{D}$; therefore, relevance criticism of $\mathrm{C}$ may either pertain to the step from $C$ to $D$, or to the steps between $D$ and the current local thesis. But the former criticism is, for the moment, excluded, since $\mathrm{O}$ conceded this step $(\mathrm{C} \rightarrow \mathrm{D})$. Consequently, relevance criticism of $\mathrm{C}$ amounts to a challenge to the Proponent to establish the second part of the chain,i.e., to defend the local thesis when $\mathrm{D}$ is granted. ${ }^{10}$

Now, consider the statements $P$ makes in the context of a direct defense move. The rules of formal dialectics prescribe that $\mathrm{O}$ attack such a statement right away. So it seems that only tenability criticism is allowed. Why this is so becomes clear upon inspection of the forms a direct defense may take. The form of a direct defense statement depends upon the form of the local thesis defended (and sometimes upon the way this thesis was criticized). If the local thesis is of the form $A \rightarrow B$, the direct defense is $B$; if it is of the form $A \vee B$, there is a choice for $P$ between $A$ and $B$ as a direct defense, etc. Thus the direct defense statements are tightly connected to the statement they are supposed to defend. So much so that there seems to be no margin for sensible criticism of the relevance type. 
Indeed the rules of formal dialectics, by not allowing such criticism, stipulate that there is no margin: if a direct defense statement were irrelevant it would not be permitted as a move. On the face of it, the connection between a conjunction $A \& B$ and its direct defenses, $A$ and B, seems less tight. One should observe, however that these defense statements each pertain to a different type of criticism on the conjunction, denoted as R? and L? respectively. So each defense is again tightly connected to the statement it defends, relative to the particular way this statement was attacked. A similar remark holds for universal statements $(\forall x A x)$.

All in all, we may conclude that each utterance of a declarative sentence by the Proponent in a formal discussion is suitably interpreted as a move in which the Proponent advances a reason for the current local thesis, and hence indirectly for the initial thesis. Given this affirmative answer to the second question, we may continue to look upon formal discussions as idealized models, restricted though they are, of reasonable argument starting from a simple conflict of opinions, and not as models merely of some special parts of a discussion.

\section{CREATIVE REASONING}

Even so, we have not really come to the heart of Van Eemeren's and Grootendorst's criticism. To say that formal discussions model reasonable argument is not to say that they do so perfectly. Indeed, it seems that one should always try for improvement, both in normative set-up and in descriptive realism. One such improvement, pertaining to the latter aspect, is clearly suggested by the present critcism.

Let us look once more at Figure 1. One may agree that A's move at line 3 conforms to argumentative practice. Formal dialectics might, therefore, gain, if this type of move could be incorporated. Not that in constructing systems of formal dialectics one aims at conformity to argumentative practice at all costs. (Rather one would like argumentative practice to conform to the norms of formal dialectics!) But even a normative system must link up with well-established practice, if it is to be a recognizable and acceptable instrument of conflict resolution.

What is most striking about A's move is that it introduces a completely new element in the discussion, namely, B. Let us, therefore, call such moves creative. Creative moves do not occur in formal discussions as hitherto defined. It is well-known that these discussions satisfy the subformula principle: each declarative sentence uttered in the discussion is a sub-sentence of some sentence comprised in the initial conflict situation. Note, however, that the subformula principle is not itself one of the basic norms of formal dialectics, but merely a consequence of its lower-level rules. ${ }^{11}$ So we may hope to be able to modify the standard systems, and do without the subformula principle, without interfering with the more basic parts of their normative set-up.

The standard systems are characterized by a very strict regulation of what utterances 
are permitted at each stage. These utterances are, in certain specified ways, syntactically linked to those made at some earlier stage. It is forbidden to bring "new" elements into the discussion. The beneficial aspect of this is that dialectics gives us clear criteria to decide the admissibility of an alleged contribution to the discussion. On the other hand, it seems unduly restrictive never to allow a Proponent to come up with some new proposition, syntactically unrelated to what went before. Rather we would like a dialectic system to guarantee the Proponent's right to reason creatively, at least as long as this does not obstruct the discussion by violating other norms. The Proponent's right to reason at all is laid down in the fundamental norm of a systematic dialectics:

FD S1 The Proponent shall be given the opportunity to attempt to defend an attacked statement of its own by making another statement, provided it assumes the pro-position toward the latter. ${ }^{12}$

This norm is neutral with respect to the kind of propositions that party P may state as reasons in support of an attacked statement of its own. But since, with the exception of the general protective defenses or winning remarks, ${ }^{13}$ all direct defense moves in formal discussions depend on the syntactic structure of the sentence to be defended, the different rules of dialectic taken together preclude creative defense moves. If this is an undesired outcome, i.e., if one sets store by creative reasoning, one may adopt the following fundamental norm of (the possibility of) creative dialectics:

FD C1 a. The opportunity granted to the Proponent in FD S1 shall include that of reasoning creatively: in some cases it must be possible for an attacked statement to be defended by a creative reason, i.e., any statement of the Proponent's choice, there being no syntactic restrictions upon this choice.

b. The Opponent should have the opportunity to criticize both the tenability and the relevance of each creative reason.

The a-part of the norm grants certain rights to the Proponent. But exercising these rights must entail some responsibilities, if the discussion is not to become incoherent. Thus, FD S1 stipulates that the Proponent be positively committed to the reasons it advances. ${ }^{14}$ In view of the other rules of formal dialectics this suffices to give the Opponent the opportunity to exert tenability criticism. (So the reference to tenability in the b-part of the new norm is really redundant.) What is new is that with creative moves the relevance can no longer be taken for granted. Consequently, party P should now take responsibility for the relevance of its stated reasons, as well as for their tenability. This is what the b-part of the new norm stipulates. Without it creativity would make discussions go haywire, as $\mathrm{P}$ could by a 'creative' move shift the topic of the discussion to any other topic of its liking, and $\mathrm{O}$ would be unable to criticize such shifts (a form of the fallacy of ignoratio elenchi).

A general and (necessarily) vague norm like FD C1 needs to be implemented by more 
specific rules. In doing so one should take care not to obstruct other aims and norms of dialectics. In the present case there is, primarily, an impending conflict with the fundamental norm of dynamic dialectics:

FD D1 The system of FD-rules applied in a discussion shall be designed to promote the revision and flux of opinions in any company in which these rules are adopted. ${ }^{15}$

In order to implement this norm, the standard systems include rules to guarantee that neither party protracts the discussion indefinitely. Clearly, the production of creative reasons will constitute a loophole in the system unless precautions are taken. Perhaps the simplest measure is to fix the number of creative moves before the actual discussion starts: 16

FD D13 At the start of the discussion P is to choose and announce an upper limit for the number of creative moves in it.

By reasoning creatively $\mathrm{P}$ introduces items in the discussion that are, on the face of it, irrelevant. $\mathrm{P}$ has to call upon O's patience to be heard out. If party $\mathrm{P}$ overplays its hand, $\mathrm{O}$ will not be willing to join in. Therefore, assuming that $\mathrm{P}$ wants to start a discussion at all, it is in P's interest to fix this limit at a modererate level.

To proceed in an orderly fashion the parties should keep count of the number of creative moves in the discussion. Since sometimes a certain utterance may be permissible, not only as a creative move, but also on account of some other right, it is important that each creative move be announced, as such. In fact, this is required by the fundamental norm of orderly dialectics. ${ }^{17}$ Let us, therefore, add:

FD 06 The Proponent shall announce each creative move by the locution enim, or some other locution the parties agree to use for this purpose. (This locution shall not, in itself, count as a move.)

Creative moves, then, will have the form 'enim $\mathrm{U}$ ', where $\mathrm{U}$ counts as a direct defense of the local thesis. The other rules of formal dialect guarantee the Opponent's right to attack $U$ (tenability criticism). It remains to implement FD C1 in such a way that the Opponent gets opportunities for relevance criticism as well. The following rule suffices:

FD C2* Each creative move consists of a locution 'enim $\mathrm{U} \&(\mathrm{U} \rightarrow \mathrm{T})$ ', where $\mathrm{T}$ is the current local thesis, and $U$ is some declarative sentence of P's choice. (U is called a creative reason for $\mathrm{T}$ ).

The formal rule for attacks on conjunctive statements permits $O$ to react in either of two ways: $L$ ? and $R$ ?. The first mode of attack constitutes tenability criticism of the reason $U$. 
The second mode constitutes relevance criticism. Unfortunately, no rule of formal dialectics forces $\mathrm{P}$ to enter, subsequently, into a discussion of the type $\mathrm{O}$ desires.The direct defense that goes with 'L?' is $U$ (leading to a discussion of U's tenability), the direct defense with ' $R$ ?' is $U \rightarrow T$ (leading to a discussion of $U$ 's relevance for $T$ ), but in either case party $\mathrm{P}$ may postpone its direct defense. ${ }^{18}$ Perhaps, therefore, one should prefer the following implementation of the creative norm:

FD C2 Each creative move consists of a locution enim U. The Opponent is to react to such a move in either of the following two ways:

a. O may attack $U$.

b. O may concede U.

( $U$ is called a creative reason for the local thesis.)

The first option for $O$ leads to a new local discussion with $U$ as its local thesis. This is, obviously, the route of tenability criticism. The second option does not lead to a new local discussion, but the introduction of the concession $\mathrm{U}$ reframes the current local discussion as one in which the Proponent is to defend the (local) thesis relative to $U$ (and to the concessions already present), i.e., in which $\mathrm{P}$ meets a challenge of irrelevance. Note that the other rules of formal dialectics are such that P's statement enim $\mathrm{U}$ does not figure in the latter discussion. Once the second line of criticism is taken, $\mathrm{O}$ is not allowed to attack this statement and $\mathrm{P}$ is no longer positively committed to it. ${ }^{19}$

\section{WINNING STRATEGIES}

Does the introduction of creative reasoning lead to new logics? Can P profit from the enlarged scope of permitted moves in the sense that this party now has a winning strategy at its disposal in some positions where no such strategy existed before? The answer is: no.

THEOREM ON CREATIVE STRATEGIES. Let $\sigma$ be any one of the standard systems of formal dialectics. ( $\sigma$ may be a system of propopositional logic, of predicate logic, or of modal logic.Moreover it may be a classical or a constructive system or a system of minimal logic.) Let $\sigma^{*}$ be the result of adding FD C1, FD C2 (or FD C2*), FD D13, and FD O6 to the rules of $\sigma$. There is a P-winning strategy for a sequent $\Pi / Z$ (i.e., for a thesis $Z$ relative to a set of initial concessions $\Pi$ ) on the strength of $\sigma$, if and only if there is a P-winning strategy for $\Pi / Z$ on the strength of $\sigma^{*}$.

One half of this theorem is trivial: if $\mathrm{P}$ has a winning strategy on the strength of $\sigma$, it may turn to the same strategy for use in $\sigma^{*}$. After all, it is $\mathrm{P}$ who decides whether to introduce any creative moves. The other half of the theorem is easily concluded from the Dialogical 
Elimination Theorem: ${ }^{20}$

DIALOGICAL ELIMINATION THEOREM. Let $\sigma$ be any one of the standard systems of formal dialectics. Assume that there are $\mathrm{P}$-winning strategies, on the strength of $\sigma$, both for $\Pi / U$ and for $\Pi, U / Z$.

Then there is a P-winning strategy, on the strength of $\sigma$, for $\Pi / Z$.

PROOF. Let $\sigma$ be some standard system. Let $\mu$ be the correlative (model-theoretic) semantic system. Then $\mu$ corresponds to $\sigma$ in the following sense:

There is a P-winning strategy for $\Pi / Z$ on the strength of $\sigma$ if and only if $Z$ is a logical consequence of $\Pi$ according to $\mu$.

(The existence of such a semantic system is guaranteed by the full circle theorem. ${ }^{21}$ ) Let us write $\Pi+Z$ for: there is a $P$-winning strategy for $\Pi / Z$ on the strength of $\sigma$; and $\Pi=Z$ for: $Z$ is a logical consequence of $\Pi$ according to $\mu{ }^{22}$ That $\sigma$ corresponds to $\mu$ can now be stated more tersely as follows:

$\Pi r Z$ if and only if $\Pi=Z$.

Since $F$ has the usual properties of semantic logical consequence, the elimination theorem becomes trivial when ' $k$ ' takes the place of ' $r$ ':

${ }^{* *} \quad$ If $\Pi \vDash U$ and $\Pi, U \vDash Z$ then $\Pi \vDash Z .^{23}$

We may now reason as follows. Suppose that $\Pi+U$ and that $\Pi, U \vdash Z$. By $\left.{ }^{*}\right)$ we conclude that $\Pi=U$ and $\Pi, U \vDash Z$. By $\left({ }^{* *}\right)$ : $\Pi \vDash Z$. By $(*)$ again: $\Pi \vdash \mathrm{Z}$. This concludes the proof.

It remains to derive the Theorem on Creative Strategies from the Dialogical Elimination Theorem.

PROOF OF THE THEOREM ON CREATIVE STRATEGIES. First, let $\sigma$ be some standard system of formal dialectics for propositional languages. Let $\sigma^{*}$ be the result of adding FD C1, FD C2, FD D13, and FD 06 to the rules of $\sigma$. Further, let $S$ be a P-winning strategy, on the strength of $\sigma^{*}$ for a sequent $\Pi / Z$. Since $S$ can be pictured as a labeled tree containing a finite number of nodes, the number of sentences that $P$, following the strategy $S$, could put forward as creative reasons must also be finite. Let these sentences be $U_{1}, \ldots$ ., $\mathrm{U}_{\mathrm{n}}$. (Which of these a Proponent, following S, will actually advance, depends of course upon the way the Opponent proceeds.) Suppose P 
advances enim $\mathrm{U}_{\mathrm{i}}$ as a creative reason. FD $\mathrm{C} 2$ stipulates that, in the next move, $\mathrm{O}$ must either attack $\mathrm{U}_{\mathrm{i}}$ or concede $\mathrm{U}_{\mathrm{i}}$. These are exactly the options $O$ has whenever $P$ attacks a concession of the form $\mathrm{U}_{\mathrm{i}} \rightarrow \mathrm{U}_{\mathrm{i}}$. Let us add statements of $U_{1} \rightarrow U_{1}, \ldots, U_{n} \rightarrow U_{n}$ to the initial concessions. This makes it unnecessary for $P$ to invoke FD C2: $P$ may now attack some $U_{i} \rightarrow U_{i}$ each time $S$ would prescribe a creative move. This shows that $P$ has in effect a winning strategy, on the strength of $\sigma$, for the sequent $\Pi, U_{1} \rightarrow U_{1}, \ldots$, $\mathrm{U}_{\mathrm{n}} \rightarrow \mathrm{U}_{\mathrm{n}} / \mathrm{Z}$. Using ' $F$ ' as in the preceding proof, we may write:

$$
\Pi, \mathrm{U}_{1} \rightarrow \mathrm{U}_{1}, \ldots, \mathrm{U}_{\mathrm{n}} \rightarrow \mathrm{U}_{\mathrm{n}} \mathrm{Z} \text {. }
$$

It is well-known that there is a P-winning strategy for $\mathrm{U}_{\mathrm{i}} \rightarrow \mathrm{U}_{\mathrm{i}}$, and hence (for each $\Pi^{\prime}$ ) for $\Pi^{\prime} / U_{i} \rightarrow U_{i}$. Hence we may write:

$(* *)$ For each $\Pi^{\prime}: \Pi^{\prime}+U_{i} \rightarrow U_{j}$.

By $\mathrm{n}$ applications of The Dialogical Elimination Theorem we may conclude that $\Pi+Z$. In other words, there is a P-winning strategy, on the strength of $\sigma$, for the sequent $\Pi / Z$. This concludes the proof for those cases where one employs a propositional language and where the creative rules are $\mathrm{FD} \mathrm{C1}$ and FD C2.

If $\mathrm{FD} \mathrm{C} 2 *$ replaces $\mathrm{FD} \mathrm{C} 2$, the argument is similar. The concessions $\mathrm{P}$ can use instead of the right to advance creative reasons now take the form $\left(\mathrm{U}_{\mathrm{i}} \&\left(\mathrm{U}_{\mathrm{i}} \rightarrow \mathrm{T}_{\mathrm{j}}\right)\right) \rightarrow \mathrm{T}_{\mathrm{i}}$, where $\mathrm{U}_{\mathrm{i}}$ is a creative reason that party $\mathrm{P}$, following its winning strategy, may advance in defense of the local thesis $T_{i}$. In a counteractive move exploiting a concession of this form, $P$ states the antecedent $U_{i} \&\left(U_{i} \rightarrow T_{j}\right)$. In the next move $O$ may attack this statement by $L$ ? or by R?. These are exactly O's options, if $P$ had advanced this statement on the strength of FD C2*. There is also a new option for $\mathrm{O}$ : to concede $\mathrm{T}_{\mathrm{i}}$. But since $T_{i}$ is the local thesis, this leads to an immediate loss for $O$.

Let us now consider those standard systems that employ quantificational languages. The problem with quantificational winning strategies is that their trees may contain an infinite number of nodes. But it is known that P-winning strategies in the quantificational standard systems can be represented by closed dialogical tableaux, and to these the preceding arguments apply. ${ }^{24}$ There is, however, one complication: a dialogical tableau does not show, in advance, what individual parameters will actually appear when party $\mathrm{P}$ follows its strategic directions. In fact, $\mathrm{P}$ may have to adapt the tableau several times during the discussion, in order to take account of O's choices of parameters. Consequently, $\mathrm{P}$ does not at the start of the discussion know what creative reasons it will possibly advance. Hence, we do not know 
what sentences to put in the list $\mathrm{U}_{1}, \ldots, \mathrm{U}_{\mathrm{n}}$. However, even if it does not tell us the parameters occurring in them, the dialogical tableau gives us all other information about these sentences. We can, therefore, meet the present difficulty by putting in as additional concessions, not the list $\mathrm{U}_{1} \rightarrow \mathrm{U}_{1}, \ldots$, $\mathrm{U}_{\mathrm{n}} \rightarrow \mathrm{U}_{\mathrm{n}}$, but a universally generalized version of this list. Let $\mathrm{a}_{1}, \ldots, \mathrm{a}_{\mathrm{m}}$ be the distinct parameters that occur in the list, and let $\mathrm{x}_{1}, \ldots, \mathrm{x}_{\mathrm{m}}$ be a list of distinct individual variables, then it suffices to replace each $a_{i}$ with $x_{i}$ throughout, and to put a string of universal quantifiers $\forall x_{1} \ldots \forall x_{m}$ in front of each conditional. The rules of quantificational dialectic sytems enable $P$ to obtain from a universally quantified concession any substitution instances it needs as further concessions.

Finally, in modal standard systems there is the complication that $\mathrm{O}$ may, under appropriate conditions, withdraw certain concessions. ${ }^{25}$ So it may not suffice to put in the mere conditionals $U_{1} \rightarrow U_{1}, \ldots, U_{n} \rightarrow U_{n}$. Rather one should, in order to immunize these against O's withdrawal rights, put in modalized versions of adequate strength. This concludes the proof.

\section{DOES THE OPPONENT ARGUE?}

Up to now we have met only with reasons, creative or other, that were (or could be) advanced by the Proponent of a thesis. This is no coincidence, for in formal discussions the Opponent does not argue for or against anything.

It is constitutive of formal discussions that the Proponent does not doubt the concessions and that the Opponent need not argue in their favour. O's positive commitment to the concessions is of another type than P's positive commitment to the thesis, i.e., it involves different obligations. $O$ has merely an obligation to 'defend' the concessions in the sense of answering P's questions ('attacks') in regard to them. P, on the other hand, has an obligation to defend the thesis, in the strong sense of making a case for it (as soon as $\mathrm{O}$ has offered critcism). ${ }^{26} \mathrm{P}$ 's defense obligation with respect to the initial thesis pervades the entire discussion, whereas O's obligation to answer a question is a local affair. In answering P's questions, party $O$ selects additional concessions it is willing to make for the sake of argument. Thus $\mathrm{O}$ steers the discussion and performs its critical role. At no point $O$ is making a case for any of its concessions. Discussions in which $O$ would do this, i.e., in which it would defend concessions in the same way party P defends its thesis, would no longer be restricted to the resolution of simple conflicts of opinion.They fall outside the scope of this paper. In any event, one could hardly say that in such discussions the Opponent argues, since no party in such discussions could be appropriately designated as the Opponent.

Nor does the Opponent argue against the Proponent's thesis, in the sense of advancing reasons for the opposite point of view. $\mathrm{O}$ attacks the thesis, and, therefore, may be said to 
criticize it (relative to the initial concessions), but criticism does not necessarily imply an opposite point of view. In the Opponent's case it certainly does not. (The concessions can, of course, not be interpreted as reasons that speak against the Proponent's thesis.)

We saw that all systems of formal dialectics incorporate opportunities for arguing. Systems complying with the fundamental norm of creative dialectics do so in a more natural and realistic way than other systems. As long as we stick to discussions that start from a simple conflict, it is the Proponent who does all the arguing, whereas the Opponent merely criticizes. Of course, if 'arguing' is taken in the broad sense of 'participating in an argumentative proces', the Opponent argues all the time. But in the narrower sense of 'arguing' stipulated in the introduction, the Opponent does not argue, and hence does not argue creatively. 


\section{NOTES}

* An earlier version of this paper appeared in Dutch: Krabbe (1985b). I am grateful to Lisa Stevens for her help in preparing an English version.

1 Van Eemeren and Grootendorst (1984), p. 13 (italics as quoted).

2 Van Eemeren and Grootendorst (1982), p.14. I have replaced their sign of conjunction by ' $\&$ '.

3 Actually, the initial conflict in Figure 2 is depicted by the first three lines, but since the move on line 4 is compulsory, this makes no difference for the present discussion.

4 A fully-fledged model of argument should of course comprise both concems.

5 To keep matters simple, I ignore the segmentation of discussions into chains of arguments, an analysis set forth in Section III.13 (Thoroughgoing dialectics) of Barth and Krabbe (1982).

6 It is also known as 'counter-attack' and 'counter-criticism', see idem, p. 59. I have come to think of these as rather infelicitous terms, since they lead one to picture the Opponent's commitment to the concessions as similar to that of the Proponent to the thesis. Cf. the last section of this paper.

7 I'm thinking of exclamations like Ipse dixisti! (You said so yourself!) and Absurdum dixisti! (You said something absurd!) Such speech acts are better looked upon, not as assertives, but as declaratives (declarations). But even if one should count them among the assertives, they would not constitute the Proponent's argumentation, since they do not belong to the argumentation stage of the discussion, but to the concluding stage. See Van Eemeren en Grootendorst (1982), p.86.

8 I'm applying Ame Naess's dichotomy of tenability and relevance. See Krabbe (1987)

9 Van Eemeren and Grootendorst (1982), p.86 and Rule 8b, p.165.

10 Perhaps one would expect an Opponent exerting relevance criticism to concede C as well as D. Surely, this would give a reasonable variant of formal dialectics. Strategically, it would make no difference.

11 See Barth and Krabbe (1982), p. 141, Lemma 6.

12 Idem, p. 63. The term 'pro-position' refers to the party P's positive commitment to its statements: in formal discussion one incurs an obligation to defend a statement to which one has the dialogue attitude of pro-position, as soon as this statement is attacked according to the rules of the dialectic system (idem, p. 58).

13 Cf. note 7.

14 Cf. note 12 .

15 Idem, p. 79.

16 An alternative would be to adopt FD D11 and FD D12 from Krabbe (1982), p. 251. These rules, and the present FD D13, belong to what Van Eemeren and Grootendorst (1982) call the opening stage of the discussion (p. 85).

17 Barth and Krabbe (1982), p. 77.

18 It can be shown, though, that such a postponement would not really be profitable to $P$; see the section on winning strategies below.

19 See idem, FD D7, p. 82. On the other hand, both lines of criticism can occur in one and the same discussion as distinct chains of arguments, see note 5 .

20 The dialogical elimination theorem is the analogue, in dialogical logic, of the proof-theoretic 
cut-elimination theorem, also known as Gentzen's Hauptsatz. See idem, XI.6.

21 Ibidem.

22 As a concrete example, take for $\sigma$ the system KND of classical dialectics for propositional languages. The semantic system $\mu$, correlative to this $\sigma$, is the ordinary system of truth table semantics. In this example, $\Pi=\mathrm{Z}$ means that there is no assignment of truth values to elementary propositions such that all the sentences in $\Pi$ come out true, whereas $\mathrm{Z}$ comes out false.

23 For instance, in truth table semantics, let $\Pi \equiv U$ and $\Pi, U \vDash Z$ hold .In order to show that $\Pi \equiv Z$, take any assignment that makes all of $\Pi$ true. We must show that $\mathrm{Z}$ comes out true under this assignment. Because of $\Pi=U, U$ is made true; hence the assignment makes all of $\Pi$ and $U$ true. Since $\Pi, U \vDash Z, Z$ is true under the assignment.

24 See Krabbe (1982), Ch 12, Essentials of the dialogical treatment of quantifiers.

25 See Krabbe (1986).

26 These two types of positive commitment are not distinguished in Barth and Krabbe (1982), where both types are labeled 'pro-position'. The point is that in the definition of the dialogue attitude of pro-position (idem, p. 58) the words 'criticism' and 'defense' can also be taken in the weak sense of 'question' and 'answer'. Cf. note 6. 


\section{REFERENCES}

Barth, E.M.: 1982,'A Normative-Pragmatical Foundation of the Rules of Some Systems of Formal 3 Dialectics', in E.M.Barth and J.L. Martens (eds.), Argumentation: Approaches to Theory Formation: Containing the Contributions to the Groningen Conference on the Theory of Argumentation, October 1978, John Benjamins, Amsterdam, pp.159-170.

Barth, E.M. and E.C.W. Krabbe: 1982, From Axiom to Dialogue: A Philosophical Study of Logics and Argumentation, Walter de Gruyter, Berlin.

Krabbe, E.C.W.: 1982, Studies in Dialogical Logic (Dissertation, Rijksuniversiteit te Groningen).

Krabbe, E.C.W.: 1985a, 'Noncumulative Dialectical Models and Formal Dialectics', Journal of Philosophical Logic 14, 129-168.

Krabbe, E.C.W.: 1985b, 'Argumentatie in formele discussies' in W.K.B. Koning (ed.), Taalbeheersing in theorie en praktijk. Lezingen van het VIOT-taalbeheersingscongres gehouden op 28, 29 en 30 augustus 1984 aan de Katholieke Hogeschool te Tilburg, Foris, Dordrecht, pp.120-128.

Krabbe, E.C.W.: 1986, 'A Theory of Modal Dialectics', Journal of Philosophical Logic 15, 206-245.

Krabbe, E.C.W.: 1987, 'Naess's Dichotomy of Tenability and Relevance' (to be published in the Proceedings of the International Conference on Argumentation, Amsterdam, June 3-6, 1986).

Lorenzen, P. and K. Lorenz: 1978, Dialogische Logik, Wissenschaftliche Buchgesellschaft, Darmstadt.

Van Eemeren, F.H. and R. Grootendorst: 1984, Speech Acts in Argumentative Discussions: A Theoretical Model for the Analysis of Discussions Directed towards Solving Conflicts of Opinion, Foris, Dordrecht, etc. 